\title{
Studies on Coking of Residual Oils (Part 4)
}

\author{
-Behavior of Sulfur in Kuwait Vacuum Residual Oil \\ during Coking Reaction- \\ by Hiromi Ozaki**, Mamoru Yamane** and Toshio Tokairin**
}

\begin{abstract}
Summary: A pyridine-soluble matter in a synthetic coal, obtained from Kuwait vacuum residual oil by a coking reaction, has been subjected to a further coking reaction. This stepwise coking reaction was carried out three times. Coking reactions of asphaltene and maltene separated from the residual oil have also been carried out at $430^{\circ} \mathrm{C}$ for $0.5,3$ and 5 hours.

It has become apparent that, in an initial step of the coking reaction, high molecular weight compounds of high sulfur content preferentially form a pyridine-insoluble matter, and it has been proposed that, in a later step, the coking reaction proceeds with cleavage of $C-S$ bonds of thiophene type compounds, resulting in partial desulfurization of the pyridine-insoluble matter.

A microscopic observation and an electron probe analysis have made it clear that sulfur is distributed homogeneously over various kinds of textures of the synthetic coal.
\end{abstract}

\section{Introduction}

A study on behavior of sulfur during coking reaction of residual oils is of great importance in relating the properties of the synthetic coal from the viewpoints of engineering as well as of basic research. In a previous paper ${ }^{1}$, Sanada et al. reported the change of sulfur concentration in the reactor bottom residue during the coking reaction of Khafji vacuum residual oil with the elapse of reaction time. They also reported that the more sulfur the feed oils contain, the easier they produce mesophase when Khafji and Minas vacuum residual oils as well as naphtha tar pitch are used as feed oils².

The present paper concerns itself with the behavior of sulfur during the coking of Kuwait vacuum residual oil which was carricd out divided into three succesive steps. It also reports the behavior of sulfur during the coking reactions of asphaltene and maltene separated from the residual oil. The distribution of sulfur in the synthetic coal obtained from the residual oil was also investigated by means of a reflected polarizedlight microscope and an electron probe microanalyser.

\section{Experimental}

\subsection{Feed Oil}

* Received July 16, 1975.

** Technical Research Centcr, Nippon Mining Co., Ltd. (3 Niizo-minami, Toda-shi, Saitama-ken 335)
Kuwait vacuum residual oil shown in our previous paper ${ }^{3)}$ was used.

\subsection{Apparatus}

The apparatus used included an autoclave $(300 \mathrm{ml})$ as previously reported ${ }^{3}$.

\subsection{Coking Procedure}

$A$ feed oil $(100 \mathrm{~g})$ was placed in the reactor and heated at a rate of $3{ }^{\circ} \mathrm{C} / \mathrm{min}$ from $300^{\circ} \mathrm{C}$ at atmospheric pressure. As soon as the testing temperature was attained, the coking reaction was started at atmospheric pressure.

\subsection{Pyridine-Soluble and Insoluble Matter}

The same method as described in our previous paper ${ }^{3)}$ was used.

\subsection{Volatile Matter}

The test method described in Methods for Proximate Analysis of Coal and Coke (JIS M 8812-1972) was used.

\subsection{Analysis of Sulfur in Gas}

Lead sulfide precipitated by bubbling the gas through $10 \%$ aqueous solution of lead acetate was analysed by the method described in JIS $M$ 8122-1959.

\subsection{Analysis of Sulfur in Oil}

The test method described in JIS K 22631970 was used.

\subsection{Analysis of Sulfur in Pyridine-Soluble and Insoluble Matters}

The method for Ultimate Analysis of Coal and Coke (JIS M 8813-1963) was used.

2.9 Analysis of Garbon and Hydrogen in 
Pyridine-Soluble and Insoluble Matters

Measurements were made with a PerkinElmer-240 elementary analyser.

\subsection{Molecular Weight Measurements}

Molecular weight measurements were carried out as described in our previous paper").

\subsection{Preparation of Asphaltene and Maltene}

Asphaltene and maltene were prepared by the method based on IP 143/57.

\subsection{NMR Measurements}

Nuclear magnetic resonance measurements were performed in the same way as described previously ${ }^{\mathbf{1}}$ with JNM- 3H-60 made by Japan Electron Optics Laboratory.

\subsection{Microscopic Observation}

Microscopic observation was done with a Leitz microscope using reflected polarized light under Xenon arc illumination.

\subsection{Electron Probe Microanalysis}

Electron probe microanalysis was conducted with TRA-25A made by Akashi Seisakusho.

\section{Results and Discussion}

Experiments were carried out on coking of Kuwait vacuum residual oil at $430^{\circ} \mathrm{C}$ for half an hour in the first step. In the second step a pyridine-solublc matter in synthetic coal (reactor bottom residue) obtained in the first step was separated and subjected to a further coking reaction at 430 C for 1 hour. In the third step a pyridinesoluble matter was separated from the synthetic coal obtained in the second step and was used as a feed oil for the subsequent coking reaction at 430 C: for 1 hour. The results are shown in Fig. 1.

\subsection{Yields of Products}

Accumulated yields of the products obtained by the stepwise coking reactions are illustrated in Fig. 2.

Changes of the slopes of the yield curves of gas, oil, pyridine-insoluble matter and the total are shown in Fig. 3. The slope of the gas yield remains almost constant through the three reaction steps. The slope of the oil yield is the largest in the first step and decreases with the movement of the reaction to the third step via the second step. The slope of the yield of the pyridine-insoluble matter is small in the first step, the largest in the second step and falls down in the third step.

Further details of the kinetics of the coking reaction will be presented in a subsequent paper.

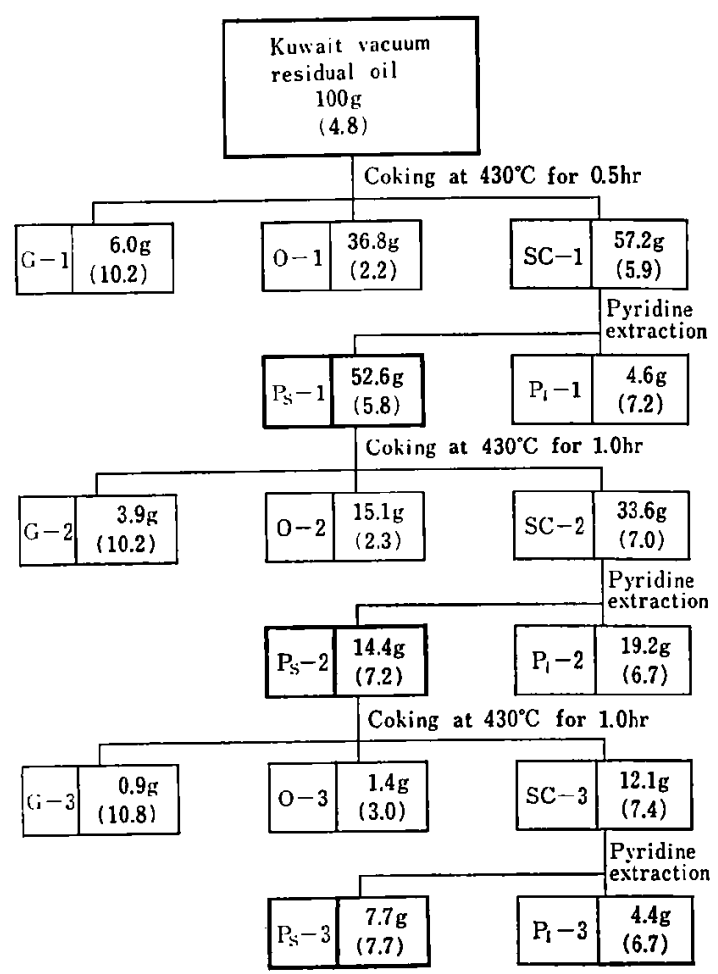

G : Gas

$\mathrm{O}: \mathrm{Oil}$

SC : Synthetic coal

$P_{S}$ : Pyridine-soluble matter in synthetic coal

$\mathbf{P}_{\mathbf{I}}$ : Pyridine-insoluble matter in synthetic coal

Numbers in parentheses : Contents of sulfur (wt \%)

Fig. 1 Yields of Products Obtained by Stepwise Coking Reactions

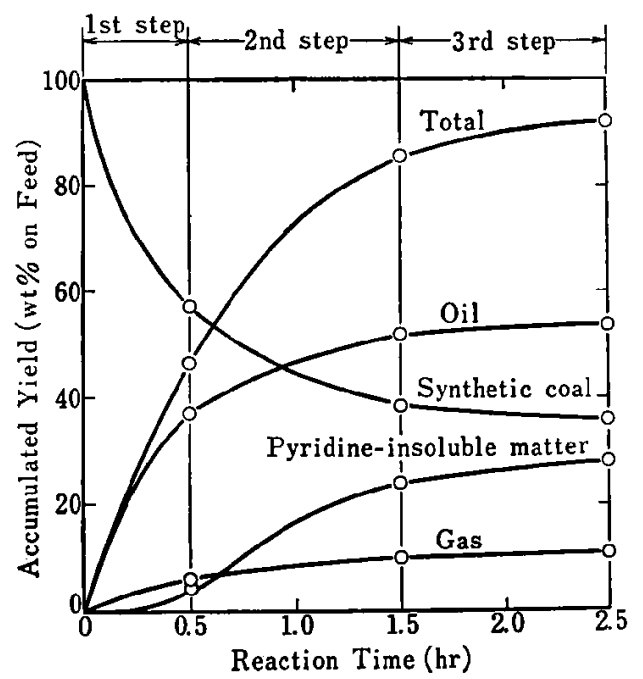

Total $=$ Gas + Oil + Pyridine-insoluble matter

Fig. 2 Accumulated Yields of Products Obtained by Stepwise Coking Reactions

\subsection{Behavior of Sulfur Contained in Kuwait Vacuum Residual Oil during Coking Reaction}

Contents of sulfur in the products of the gas, 


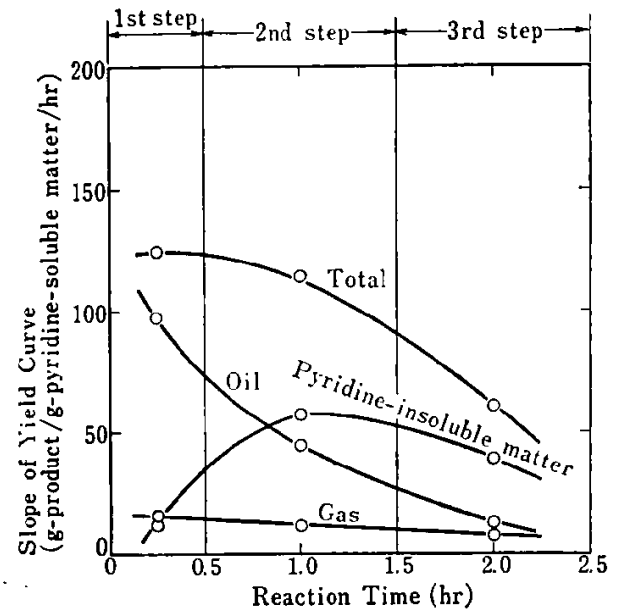

Total $=$ Gas + Oil + Pyridine-insoluble matter

Fig. 3 Slope of Yield Curve in Each Step of Coking Reaction

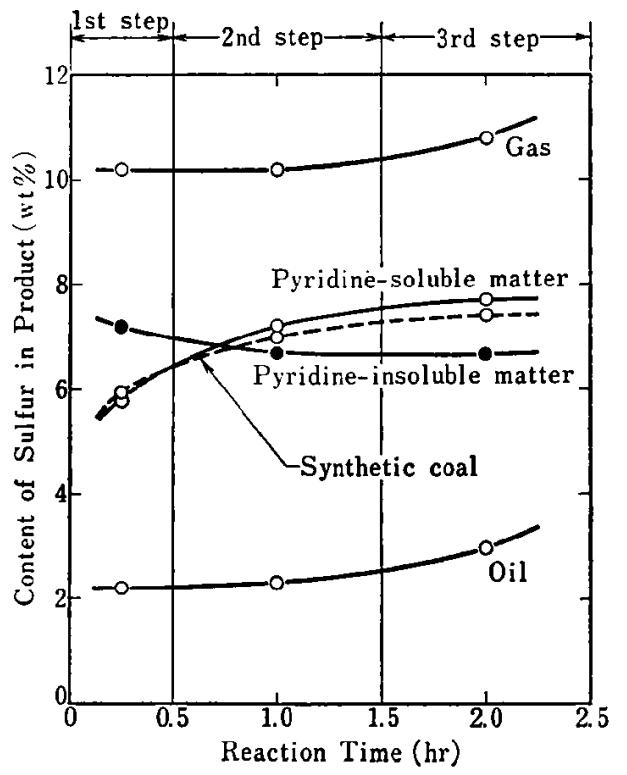

Fig. \& Changes of Contents of Sulfur in Products Ottained in Each Step of Coking Reaction

oil, pyridine-soluble and insoluble matters obtained in each reaction step are shown in Fig. 4.

Accumulated contents of sulfur in the products are shown in Fig. 5. The curve of $\%$ sulfur in the synthetic coal against coking reaction time was found similar to the one presented by Sanada et al. on Khafji vacuum residual oil ${ }^{11}$.

It can be seen that the sulfur contents in the gas and the oil obtained in each step slowly increase with the movement of the reaction step from the first to the second and the third (Fig. 4). However, the accumulated contents of the sulfur in the products of the gas and oil stay almost constant while the reaction time elapses (Fig. 5).

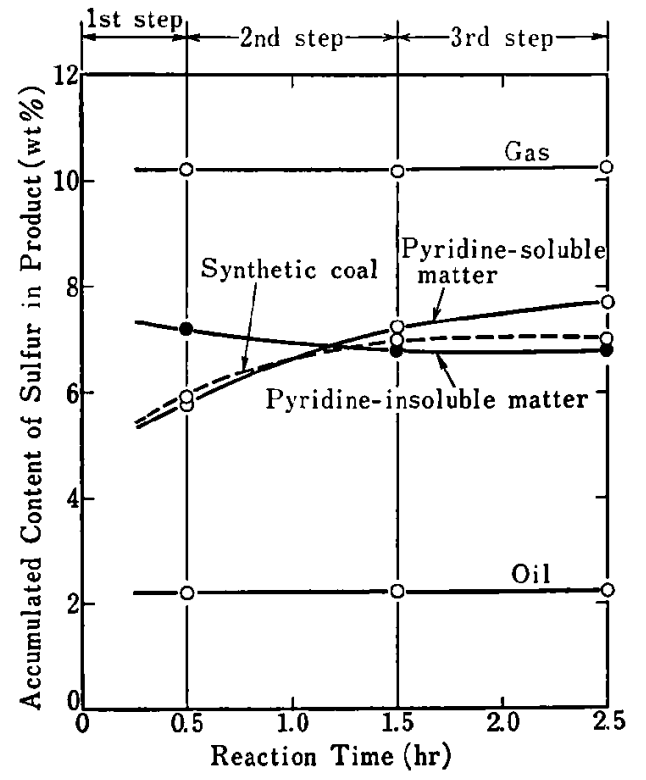

Fig. 5 Accumulated Contents of Sulfur in Products Obtained by Stepwise Coking Reaction

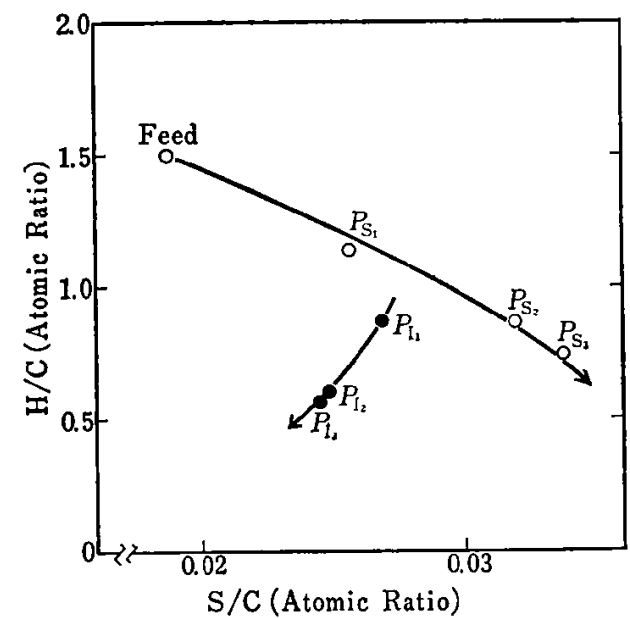

Fig. $6 \mathrm{H} / \mathrm{C}-\mathrm{S} / \mathrm{C}$ Diagram for Pyridine-Soluble and Insoluble Matters

It was found that the sulfur content in the pyridine-soluble matter increases when the coking reaction proceeds from the first step to the second and third. In contrast, decrease of the sulfur content in the pyridine-insoluble matter is observed with the elapse of the reaction time (Figs. 4 and 5 ).

According to the idea presented by Sanada et al. ${ }^{1)}$, the relation between $\mathrm{H} / \mathrm{C}$ ratio and $\mathrm{S} / \mathrm{C}$ ratio of the pyridine-soluble and insoluble matters are illustrated in Fig. 6, where it is recognized that the further the coking reaction procecds, the more dehydrogenation and concentration of sulfur occur to the pyridine-soluble matter. In contrast, decrease in $\mathrm{S} / \mathrm{C}$ ratio occurs to the pyridine-

Volume 17, No. 2, November 1975 

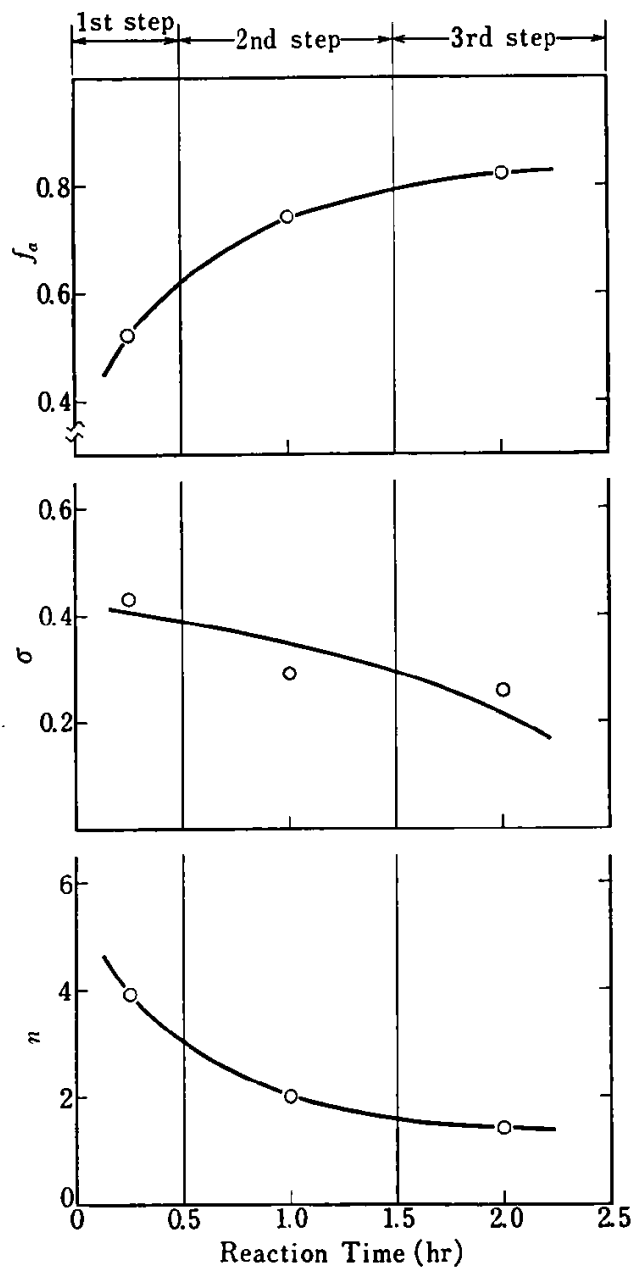

Fig. 7 NMR Derived Parameters of Pyridine-Soluble Matter in Synthetic Coal Obtained in Each Step of Coking Reaction

insoluble matter with the proceeding of the coking reaction, though the dehydrogenation takes place as in the case of the pyridine-soluble matter.

Aromaticity $\left(f_{a}\right)$, degree of substitution to aromatic rings $(\sigma)$ and number of $\mathrm{C}$ atoms in the side chains of the aromatics ( $n$ ) of pyridinesoluble matter were determined by means of NMR spectrometry as shown in Fig. 7. It is apparent that scissions of the side chains of the aromatics take place and the aromaticity of the pyridinesoluble matter becomes higher with the proceedings of the coking reaction.

These facts described above with Figs. 4 7 suggest that, in the first step, such compounds as contained in the asphaltene fraction of high sulfur content are preferentially converted to the pyridine-insoluble matter. In the second and third steps, however, such compounds as contained in other fractions than asphaltene should react as a feed, so it is assumed that the poly- merization-condensation of the oil should occur with desulfurization caused by cleavage of some carbon-sulfur bonds in the condensed aromatic rings, resulting in lower sulfur content in the pyridine-insoluble matter than the pyridinesoluble matter.

\subsection{Behavior of Sulfur in Asphaltene and Maltene of Kuwait Vacuum Residual Oil during Coking Reaction}

In order to investigate further details of the behavior of the sulfur during the coking reaction, Kuwait vacuum residual oil was separated into asphaltene and maltene, each of which was subjected to the coking reaction at $430^{\circ} \mathrm{C}$ for $0.5,3$ and 5 hours. The results are shown in Figs. 8 11 .

Figure 9 shows that the asphaltene is converted to the pyridine-insoluble matter much faster than the maltene and its yield from asphaltene is higher than that from the maltene. This phenomenon can well explain the previous experimental result ${ }^{5}$ ) that Khafji vacuum residual oil, which contains more asphaltene than Minas vacuum residual oil, produces pyridine-insoluble matter faster than Minas vacuum residual oil. Moreover, it is obvious in Fig. 10 that the pyridine-insoluble matter from the asphaltene has lower volatile matter than the one from the maltene. These are because the molecular weight of the asphaltene is large enough to form the pyridine-insoluble matter by a slight polymerization-condensation reaction, initiated and propagated by the free radicals formed by scission of C:- $:$ : bonds in the side chains which have almost no sulfur ${ }^{\mathbf{4}),(6) \sim 8)}$, and this may be the reason why the sulfur content of the pyridine-insoluble matter made from the asphaltene is almost the same as that of the pyridine-soluble matter throughout the coking reaction as shown in Fig. 11.

In contrast, the sulfur content of the pyridineinsoluble matter made from the maltene is found lower than that of the pyridine-soluble matter except at the early stage of the coking reaction. The reason for this is assumed as follows: further polymerization-condensation is necessary to convert the maltene to pyridine-insoluble matter than to convert the asphaltene since the former has smaller average molecular weight $(800)$ than the latter (2360), and cleavage of C-S bond, which is a thiophene type ${ }^{4), 6) \sim 8)}$ and weaker than the aromatic ( $\mathrm{C}-\mathrm{C}$ bond, is required to form free radicals to propagate the further polymeri- 


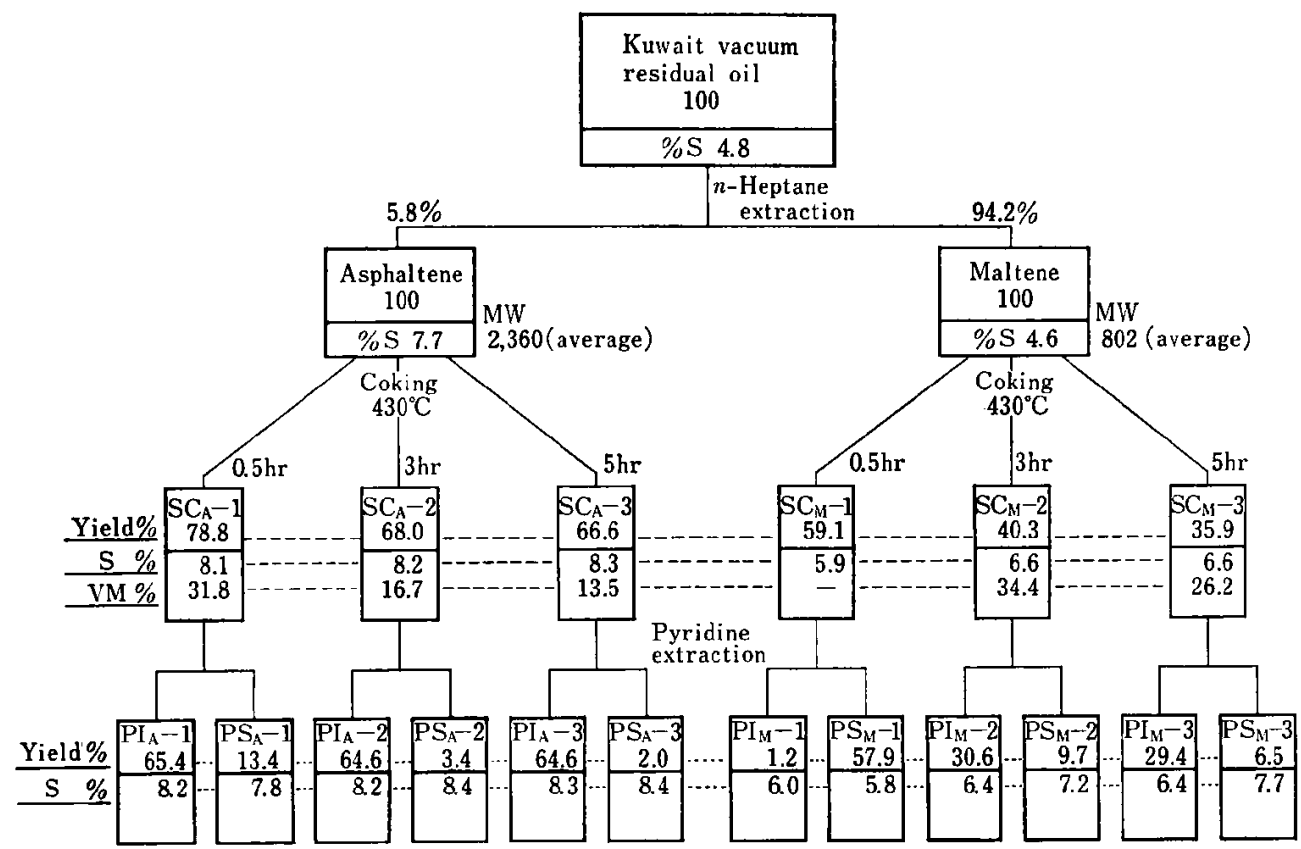

$\mathrm{SC}_{\mathrm{A}}$ : Synthetic coal from asphaltene, $\mathrm{SC}_{\mathrm{M}}$ : Synthetic coal from maltene, $\mathrm{PI}_{\mathrm{A}}$ : Pyridineinsoluble matter in $\mathrm{SC}_{\mathrm{A}}, \quad \mathrm{PI}_{\mathrm{M}}$ : Pyridine-insoluble matter in $\mathrm{SC}_{\mathrm{M}}, \mathrm{PS}_{\mathrm{A}}$ : Pyridine-soluble matter in $\mathrm{SC}_{\mathrm{A}}, \mathrm{PS}_{\mathrm{M}}$ : pyridine-soluble matter in $\mathrm{SC}_{\mathrm{M}}$

Fig. 8 Yields of Products Obtained by Coking Reactions of Asphaltene and Maltene Separated from Kuwait Vacuum Residual Oil

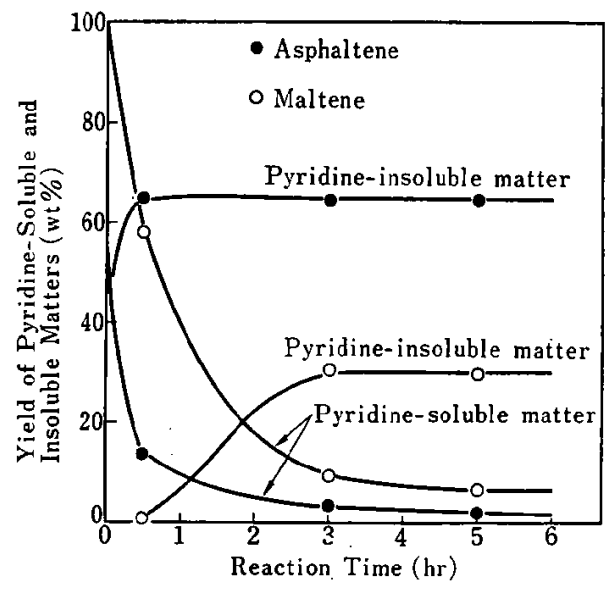

Fig. 9 Relation between Reaction Time and Yields of Pyridine-Soluble and Insoluble Matters Obtained from Asphaltene and Maltene

zation-condensation reaction after the scissions of the side-chains have all occurred, thus liberating sulfur as hydrogen sulfide and resulting in partial desulfurization of the pyridine-insoluble mattcr.

The behavior of sulfur mentioned above could be roughly outlined as shown in Fig. 12.

\subsection{Microscopic Observation and Electron Probe Analysis of Synthetic Coal}

In order to obtain information on the actual distribution of sulfur on the surface of synthetic coal, polarized-light microscopic observation and

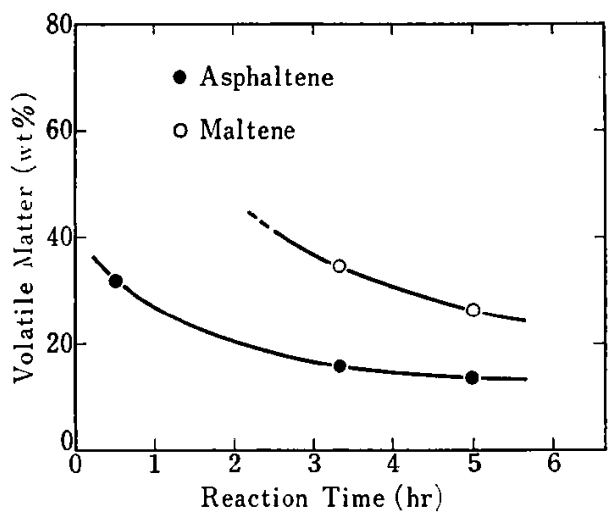

Fig. 10 Relation between Reaction Time and Volatile Matter in Pyridine-Insoluble Matter Obtained from Asphaltene and Maltene

Table 1 Inspections of Synthetic Coal used for Microscopic Observation and Electron Probe Analysis

\begin{tabular}{ll|r}
\hline Carbon & $(w t \%)$ & 87.6 \\
Hydrogen & $(w t \%)$ & 3.5 \\
Sulfur & $(w t \%)$ & 7.5 \\
Nitrogen & $(w t \%)$ & 0.9 \\
Volatile Matter & $(w t \%)$ & 9.6 \\
\hline
\end{tabular}

electron probe analysis were made. The properties of the used synthetic coal, made fromK uwait vacuum residual oil by the coking reaction at $430^{\circ} \mathrm{C}$ for 9 hours, are shown in Table 1.

Various kinds of textures such as fine mosaic,

Volume 17, No. 2, November 1975 
$a$

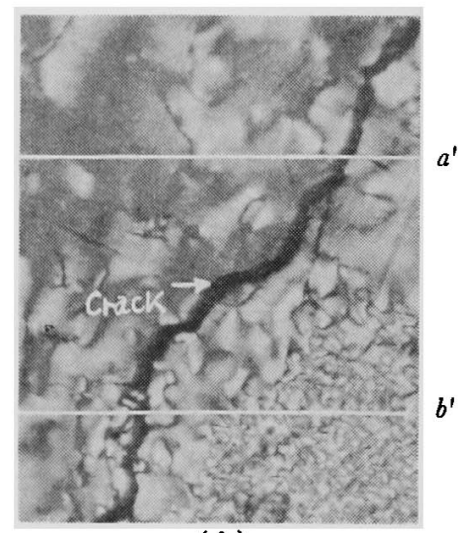

( I)

$a$

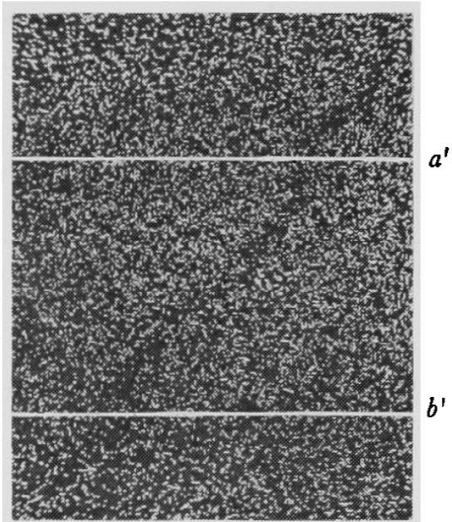

(2)

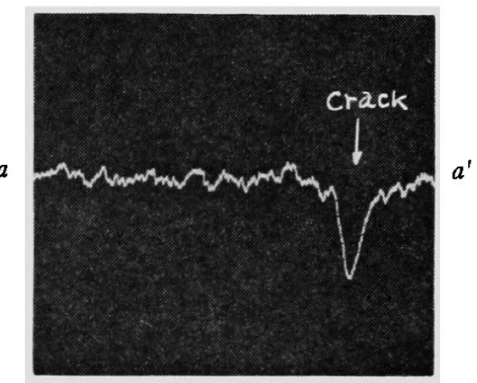

(3)

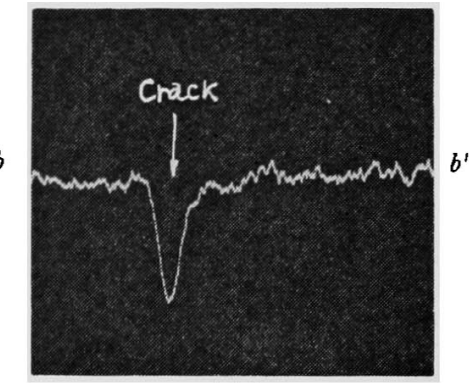

(4)

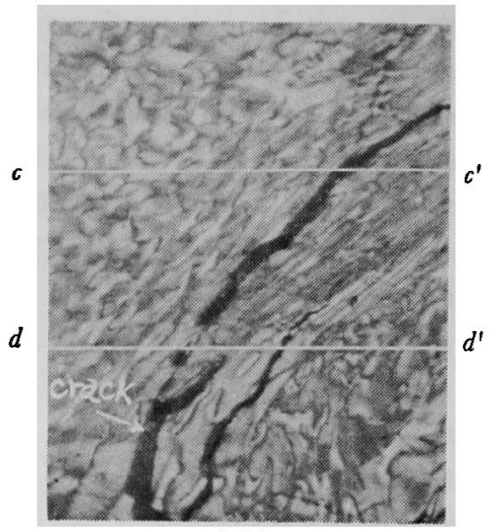

(5)

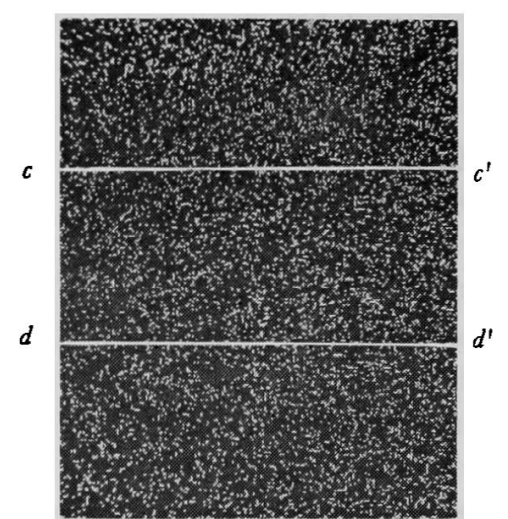

(6)

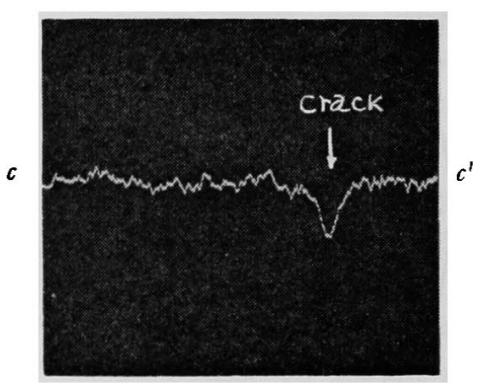

(7)

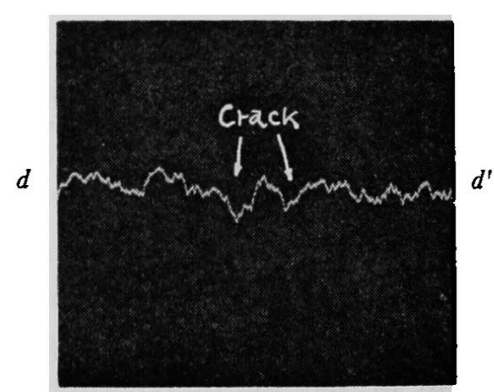

(8)

(1), (5) : Micrograph of synthetic coal by reflected polarized light

(2), (6) : X-ray image of surface of synthetic coal by $\mathrm{SK}_{\alpha}$

(3), (4), (7), (8) : Line scanning profile of cross section of synthetic coal

Fig. 13 Sulfur Distributions over Various Kinds of Textures of Synthetic Coal 


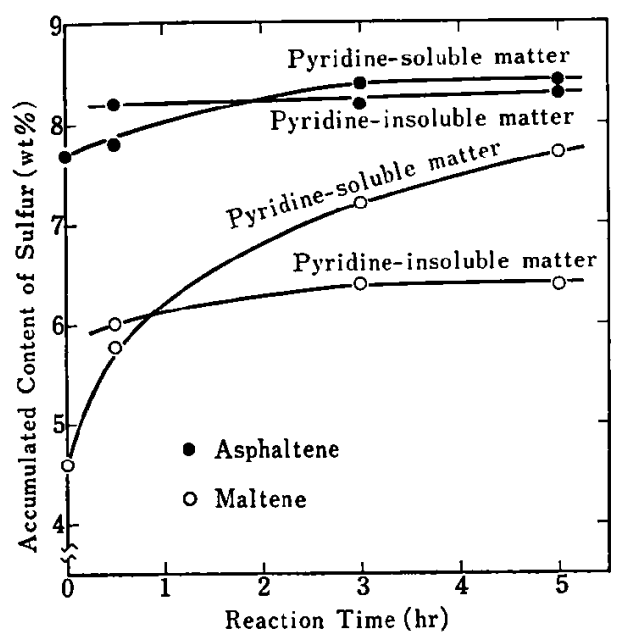

Fig. 11 Relation between Reaction Time and Contents of Sulfur in Pyridine-Soluble and Insoluble Matters Obtained from Asphaltene and Maltene

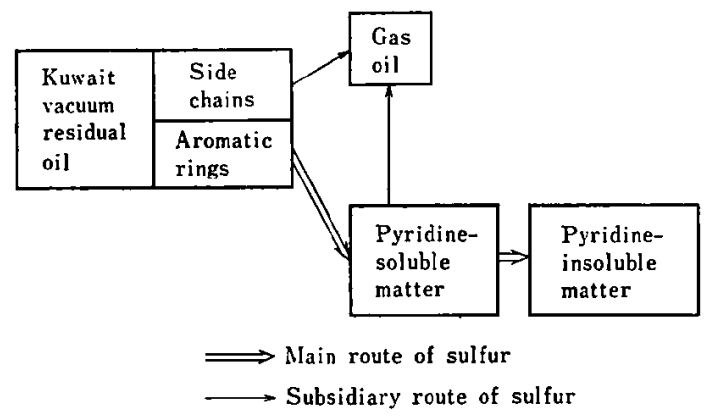

Fig. 12 Routes of Sulfur during Coking Reaction

coarse mosaic and needle-like are observed in Fig. 13 (1) and (5). Line analyses were made across these textures and the distributions of sulfur over these textures were investigated. No difference in sulfur content was found among these textures in Fig. $13(2) \sim(4)$ and $(6) \sim(8)$.

It was previously reported ${ }^{1)}$ that the sulfur contained in or added to feed oils tends to change textures of synthetic coals made by coking reactions. Therefore, heterogeneous distribution of sulfur is expected to be observed because it is considered that the synthetic coal of high sulfur content made in the initial step of the coking reaction will have a different texture from the one of low sulfur content made in the later step. The observed results indicate, however, that it is quite difficult to pick out a part of low sulfur content from the synthetic coal with the intention of desulfurization of the synthetic coal.

\section{Conclusion}

Stepwise coking reactions of Kuwait vacuum residual oil as well as coking reactions of asphaltene and maltene separated from the residual oil have made it apparent that high molecular weight compounds of high sulfur content preferentially form a pyridine-insoluble matter in the initial step of coking reaction, and it has been proposed that, in the later step, the coking reaction proceeds with cleavage of $\mathrm{C}-\mathrm{S}$ bonds of thiophene type compounds in the feed, resulting in partial desulfurization of the pyridine-insoluble matter.

A microscopic observation and an electron probe analysis have made it clear that sulfur is distributed homogeneously over various kinds of textures of the synthetic coal.

\section{Acknowledgment}

The authors wish to express their appreciation to Mr. M. Ogawa, General Manager of Technical Research Center, Nippon Mining Company for permission to publish this paper, and to $\mathrm{Mr}$. $\mathrm{Y}$. Tajima and Mr. K. Ikuta of the Technical Research Center for the microanalysis and microscope works.

\section{References}

1) Sanada, Y., Furuta, T., Kumai, J., Kimura, H., J. Japan Petrol. Inst., 16, (5), 404 (1973).

2) Sanada, Y., Furuta, T., Kumai, J., Kimura, H., ibid., 16, (11), 902 (1973).

3) Ozaki, H., Yamane, M., Yoshikai, H., ibid., 17, (10), 879 (1974).

4) Ozaki, H., Yamane, M., Yoshikai, H., ibid., 17, (10), 885 (1974).

5) Sanada, Y., Furuta, T., Kumai, J., Kimura, H. ibid., 16, (5), 409 (1973).

6) Bestougeff, M., 5th World Petroleum Congr., Section V-Paper 12, 143 (1959).

7) Drushel, H. V., Sommers, A. L., Anal. Chem., 39, (14), 1819 (1967).

8) Dean, R. A., Whitehead, E. V., 7th World Petroleum Congr., Proc., 9, 165 (pub. 1968). 